\title{
EFFECT OF PROCESSING/MICROSTRUCTLRE ON THE THRESHOLD FATIGUE CRACK GROWTH BEHAVIOR OF ALLOY 718 FORGING
}

\author{
Bermard H. Lawless" and A.W. Dix \\ *GE Aircraft Engines \\ Materials \& Process Engineering Department \\ Cincinnati, Ohio \\ *** GE Aircraft Engines \\ Materials \& Process Engineering Department \\ Lynn, MA
}

\begin{abstract}
The threshold fatigue crack growth behavior of Alloy 718 forging was investigated from room temperature to $538^{\circ} \mathrm{C}$. For grain sizes equal to or smaller than ASTM GS 10 (i.e., ASTM grain size number of 10 or larger), the measured thresholds were insensitive to prior forging processing history. For a given forging/heat treat practice, the measured threshold stress intensities increased with increasing temperature. This temperature effect became more pronounced with decreasing grain size. The measured threshold stress intensities appear to be related to grain size; at a given temperature, the largest value of threshold stress intensity was obtained for the coarse grain material (ASTM grain size 3). This grain size effect was greatest at low temperature, and diminished with increasing temperature.
\end{abstract}

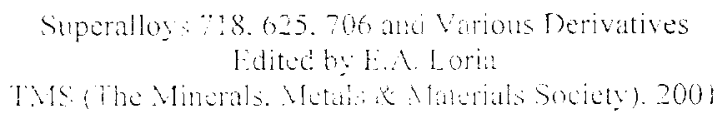




\section{Background}

Alloy 718 is widely used in aircraft engine rotor structures. Because of the combination of microstructural phases and aging response, Alloy 718 forgings can be thermomechanically worked to obtain a wide range of microstructures and mechanical properties.[1] The effect of changes in thermomechanical processing on the threshold fatigue crack growth behavior of Alloy 718 are described in this work.

\section{Materials and Processing}

Three processing versions of Alloy 718 were examined in this work:

$\begin{array}{ll}\text { Process } & \text { Acronym } \\ \text { Direct aged } & \text { "DA" } \\ \text { Mini grain } & \text { "MG" } \\ \text { Coarse grain } & \text { "CG" }\end{array}$

\section{Direct aged}

For this version of Alloy 718 , the material is direct aged after forging with no intermediate solution heat treatment. Large forging reductions at low temperatures are used to achieve a fine, uniform grain size which is typically finer than ASTM GS 10.[1] The material receives the standard duplex heat treatment after forging $\left(718^{\circ} \mathrm{C} / 8\right.$ hrs $+621^{\circ} \mathrm{C} / 8$ hrs $)$. A typical microstructure can be seen in Figure l(a). The grain size is estimated to be ASTM GS 13.

\section{Mini grain}

This material was forged from ultra fine grain billet [2], solution heat treated at $970^{\circ} \mathrm{C}$, and then duplex aged $\left(718^{\circ} \mathrm{C} / 8 \mathrm{hrs}+621^{\circ} \mathrm{C} / 8 \mathrm{hrs}\right)$. A typical microstructure can be seen in Figure 1 (b). The grain size is a little finer than ASTM GS 10. The grain size of the direct aged (DA) process is finer than the grain size of the mini-grain (MG) process.

\section{Coarse grain}

A remnant from a fine grain forging was solution heat treated for five hours at $1010^{\circ} \mathrm{C}$, and then duplex aged $\left(718^{\circ} \mathrm{C} / 8 \mathrm{hrs}+621^{\circ} \mathrm{C} / 8 \mathrm{hrs}\right)$. A typical microstructure can be seen in Figure 1(c). The $1010^{\circ} \mathrm{C}$ solution heat treatment has caused significant grain growth to occur. The grain size is estimated to be ASTM GS 3.

\section{Specimen Geometry and Test Technique}

Crack growth testing was performed using the button head single edge notch (SENBH) specimen, which can be seen in Figure 2. The nominal gage section was $10.2 \mathrm{~mm}$ wide $\times 2.5$ $\mathrm{mm}$ thickness. All of the data were acquired using the direct current electrical potential drop technique. This technique is a modification of the method described by Gangloff.[3] The direct current potential drop technique has been adapted to the single edge notch geometry by Wilcox and Henry. [4] The potential solution developed by Johnson [5] was used to convert potential data to crack length data. Crack growth rates werc calculated using the seven point polynomial method. Stress intensity values for the button head single edge notch specimen were calculated using the Harris solution [6], based on the analysis of Gilbert and Malik.[7] 

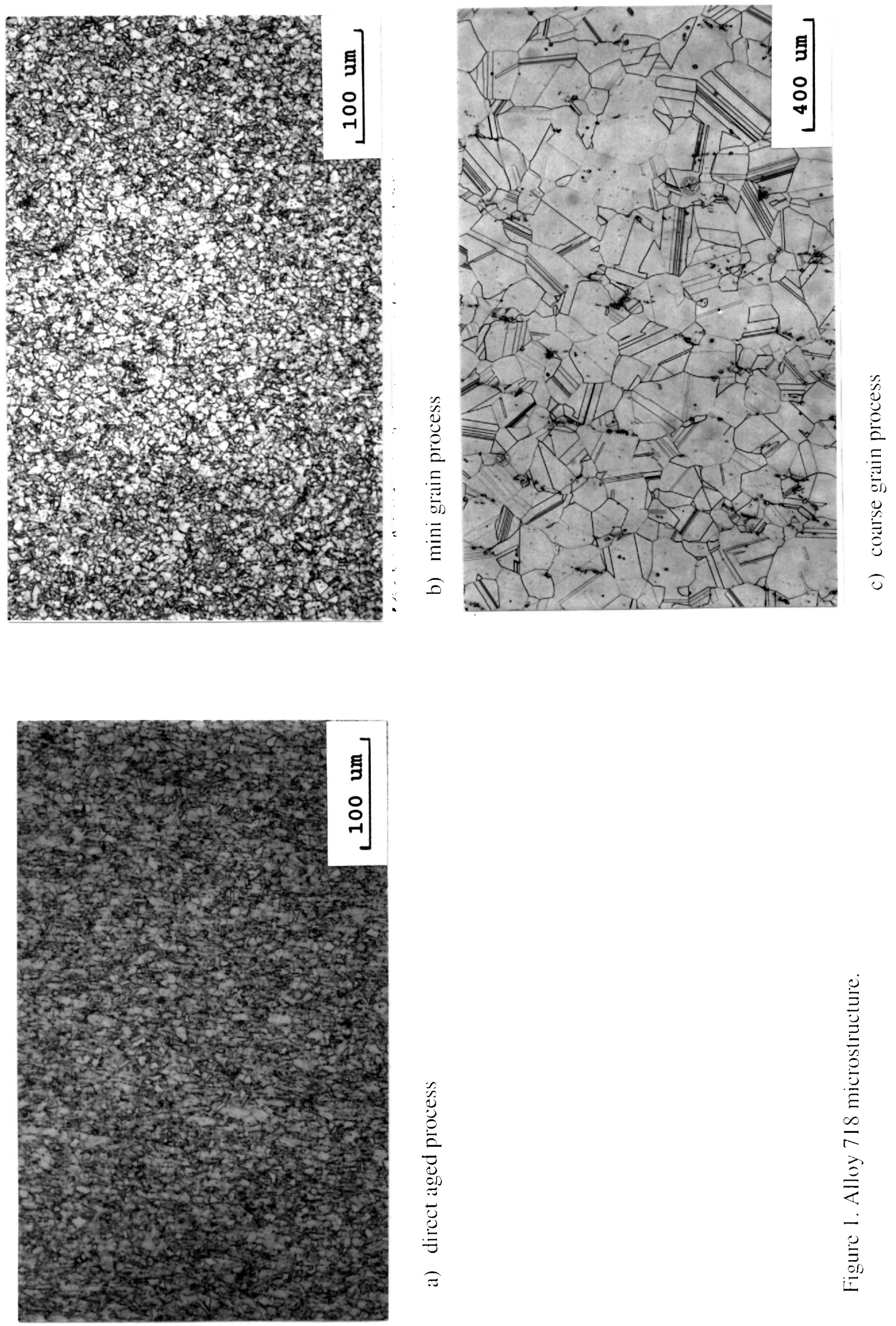

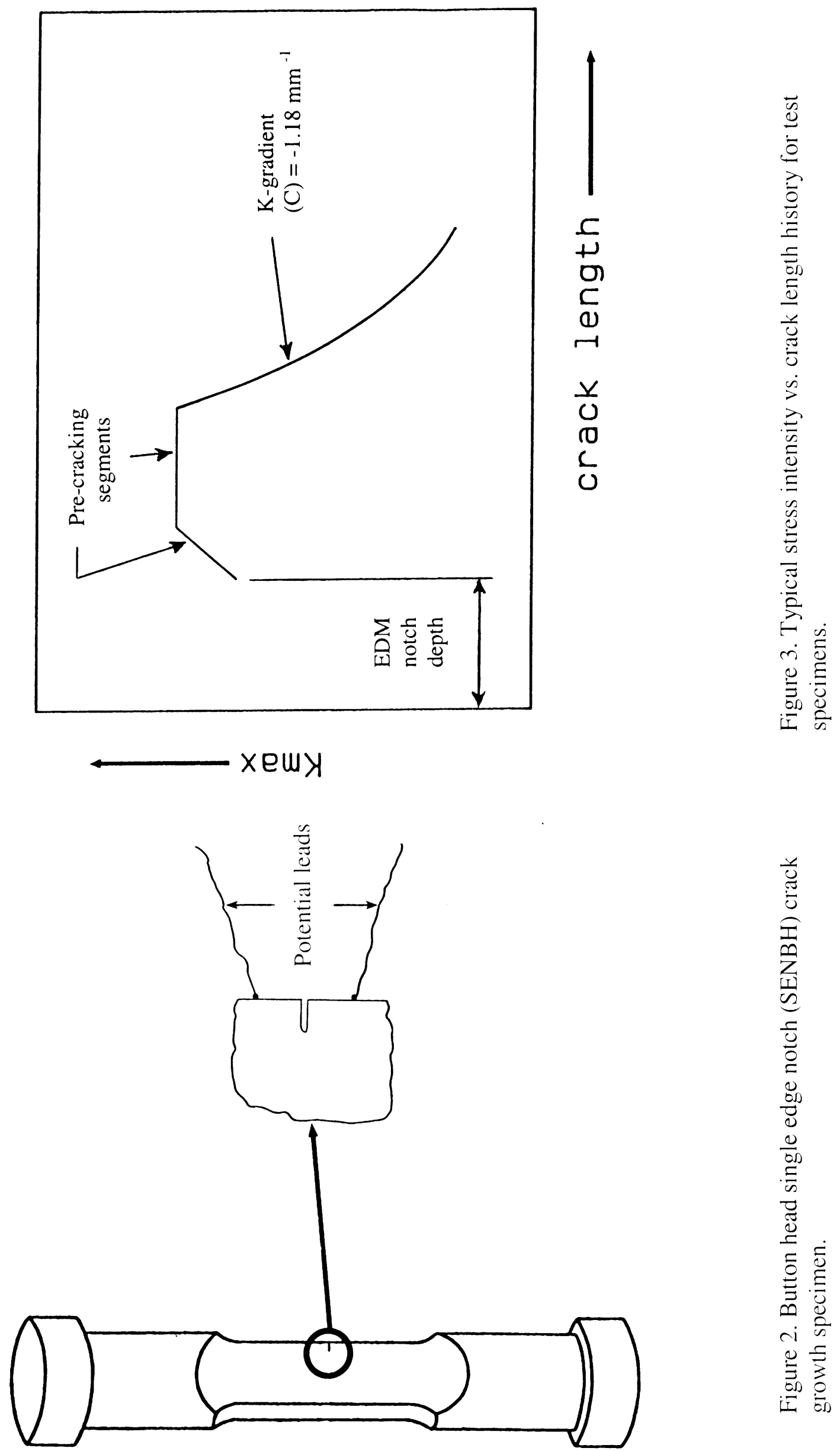
All testing was performed at $\mathrm{R}$ ratio $=0$ and a frequency of $0.33 \mathrm{~Hz}$. All tests were performed using the following procedure, which is shown schematically in Figure 3:

Step 1: A fatigue precracking segment where the specimen was cycled at a constant load range. Therefore, both $\mathrm{Kmax}$ and $\Delta \mathrm{K}$ increased as the fatigue crack propagated.

Step 2: Another fatigue precracking segment where the specimen was cycled at a constant value of Kmax.

Step 3: A segment of decreasing $\Delta \mathrm{K}$ where $\Delta \mathrm{K}$ is decreased or shed until apparent crack arrest. A K-gradient $(\mathrm{C})=-1.18 / \mathrm{mm}$ was used for all tests. For other nickel-base superalloys with similar strength level, Henry [8] has shown that this shed rate falls within a range of shed rates where the near threshold fatigue crack growth rates are not affected by a variation in $\mathrm{C}$.

Steps (1) through (3) were repeated for selected experiments to obtain two threshold measurements from a single specimen. Crack arrest was defined to be a crack growth rate of approximately 2 to $4 \times 10^{-10} \mathrm{~m} / \mathrm{cycle}$.

\section{Results}

Tensile data were obtained for all three Alloy 718 processes, and are summarized in Table I.

Table I Tensile Data for Alloy 718

$$
(\text { Units }=\text { MPa })
$$

\begin{tabular}{|c|c|c|c|c|c|c|}
\hline \multirow{2}{*}{$\begin{array}{l}\text { Temp } \\
\left({ }^{\circ} \mathrm{C}\right)\end{array}$} & \multicolumn{2}{|c|}{$\begin{array}{c}\text { Direct aged } \\
\text { ("DA") }\end{array}$} & \multicolumn{2}{|c|}{$\begin{array}{l}\text { Mini grain } \\
\text { ("MG") }\end{array}$} & \multicolumn{2}{|c|}{$\begin{array}{c}\text { Coarse grain } \\
(" \mathrm{CG} \text { (") }\end{array}$} \\
\hline & $0.2 \mathrm{YS}$ & UTS & $0.2 \mathrm{YS}$ & UTS & $0.2 \mathrm{YS}$ & LTS \\
\hline 24 & 1286 & 1512 & 1170 & 1465 & 1220 & 1465 \\
\hline 400 & 1180 & 1354 & 1054 & 1275 & 1115 & 1305 \\
\hline
\end{tabular}

The largest values of yield strength were obtained for the DA process. The yield strength values for the $\mathrm{CG}$ process were larger than for the MG process, which exhibited the lowest yield strength.

The values of $\Delta \mathrm{K}$ at apparent crack arrest (i.e., the $\Delta \mathrm{K}$ threshold) are listed in Table II, and plotted as a function of temperature in Figure 4. Figure 4 shows that the threshold values increase with increasing temperature. There is a significant temperature effect for the two fine grain versions of Alloy 718; however, the temperature effect is much smaller for the coarse grain Alloy 718 . 

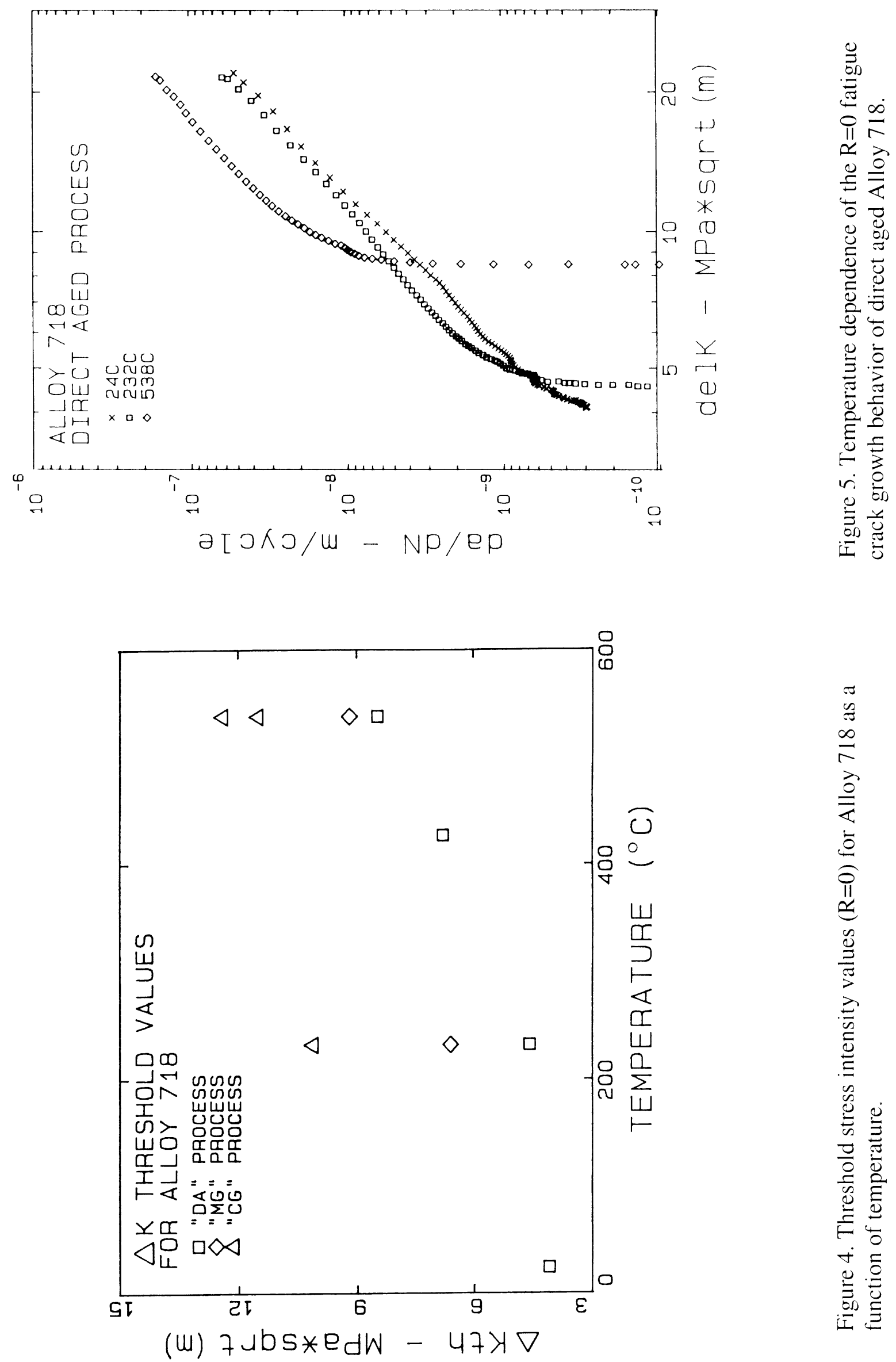

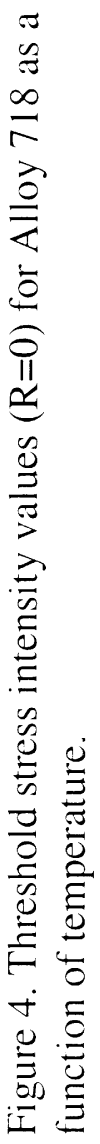


Table II Threshold Values for Alloy 718

$($ Units $=$ MPa $\vee \mathrm{m})$

\begin{tabular}{cccc}
\hline & & & \\
& & & \\
$\left({ }^{\circ} \mathrm{C}\right)$ & $\begin{array}{c}\text { Direct aged } \\
(" \mathrm{DA} ")\end{array}$ & $\begin{array}{c}\text { Mini grain } \\
(" \mathrm{MG} ")\end{array}$ & $\begin{array}{c}\text { Coarse grain } \\
(\text { "CG") }\end{array}$ \\
\hline 24 & 4.1 & 6.6 & 10.1 \\
232 & 4.6 & & \\
427 & 6.8 & $9.2,9.2$ & $11.5,12.4$ \\
538 & 8.5 & & \\
\hline
\end{tabular}

\section{Discussion}

\section{"Crossover" in fatigue crack growth rate}

A "crossover" in fatigue crack growth rate with increasing temperature was observed for all three versions of Alloy 718. The temperature dependent fatigue crack growth rate data are plotted for the direct aged, mini grain, and coarse grain processes in Figures 5, 6, and 7, respectively. The observation of the crossover behavior in direct aged Alloy 718 agrees with a previous investigation of direct aged Alloy 718.[9] Examination of Figures 5 through 7 indicates that the magnitude of the crossover effect is greater in fine grain Alloy 718 (the "DA" and "MG" processes) than in coarse grain Alloy 718 (the "CG" process). In the direct aged Alloy 718 , the $24^{\circ} \mathrm{C}$ and $232^{\circ} \mathrm{C}$ results exhibit little difference in Region I and Region II behavior. The threshold value at $232^{\circ} \mathrm{C}$ is a little greater than the $24^{\circ} \mathrm{C}$ result. However, there is a greater crossover effect between $232^{\circ} \mathrm{C}$ and $538^{\circ} \mathrm{C}$, and a much larger value of threshold was obtained at $538^{\circ} \mathrm{C}$.

\section{Temperature dependence of the threshold}

The temperature dependence of the threshold in the two fine grain versions of the alloy are similar to the temperature dependence observed in the previous investigation of direct aged Alloy 718.[9] In the previous investigation of direct aged Alloy 718, it was suggested that localized crack tip blunting by plasticity and/or creep could account for the increase in threshold with increasing temperature. The concept of local crack tip creep contribution to crack tip blunting is further supported by the observation that, at a given elevated temperature, decreasing the test frequency results in an apparent increase in thresholds in both Rene'95 and Alloy 718.[10]

\section{Coarse grain vs fine grain behavior}

The coarse grain Alloy 718 exhibited lower Region I and Region II crack growth rates than the fine grain versions of Alloy 718 at each temperature. The crack growth data for each of the three processes are plotted in Figures 8 and 9 for $232^{\circ} \mathrm{C}$ and $538^{\circ} \mathrm{C}$, respectively. These results are in agreement with a previous investigation of the effect of grain size on the fatigue crack growth behavior of Alloy 718 at $427^{\circ} \mathrm{C}$. [11] In that investigation, the improved fatigue crack growth resistance of the coarse grain microstructure was explained on the basis of slip character and dislocation reversibility. The longer slip bands in the coarser microstructure were believed to better accommodate dislocation reversal since the distance between dislocation pile-up 

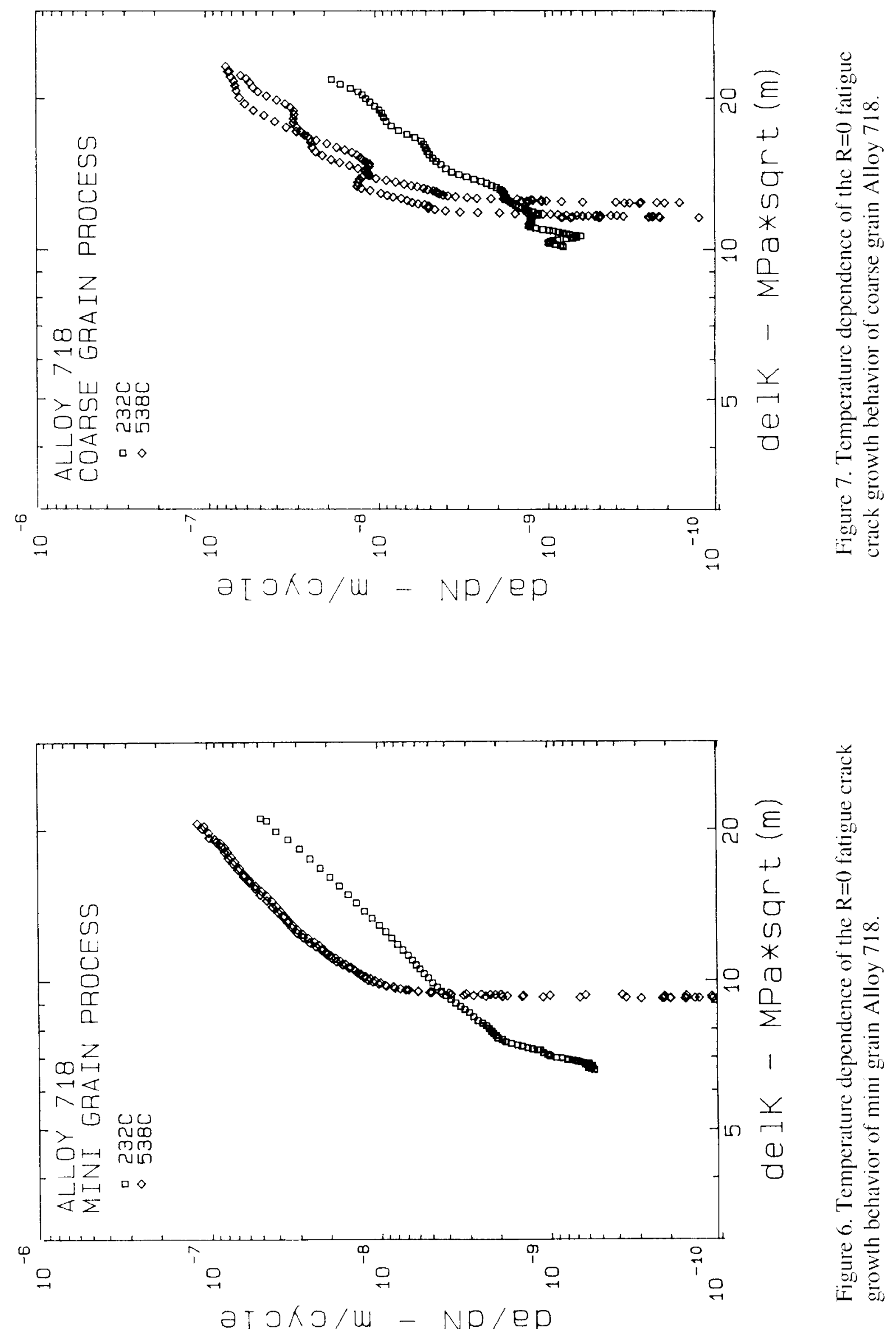

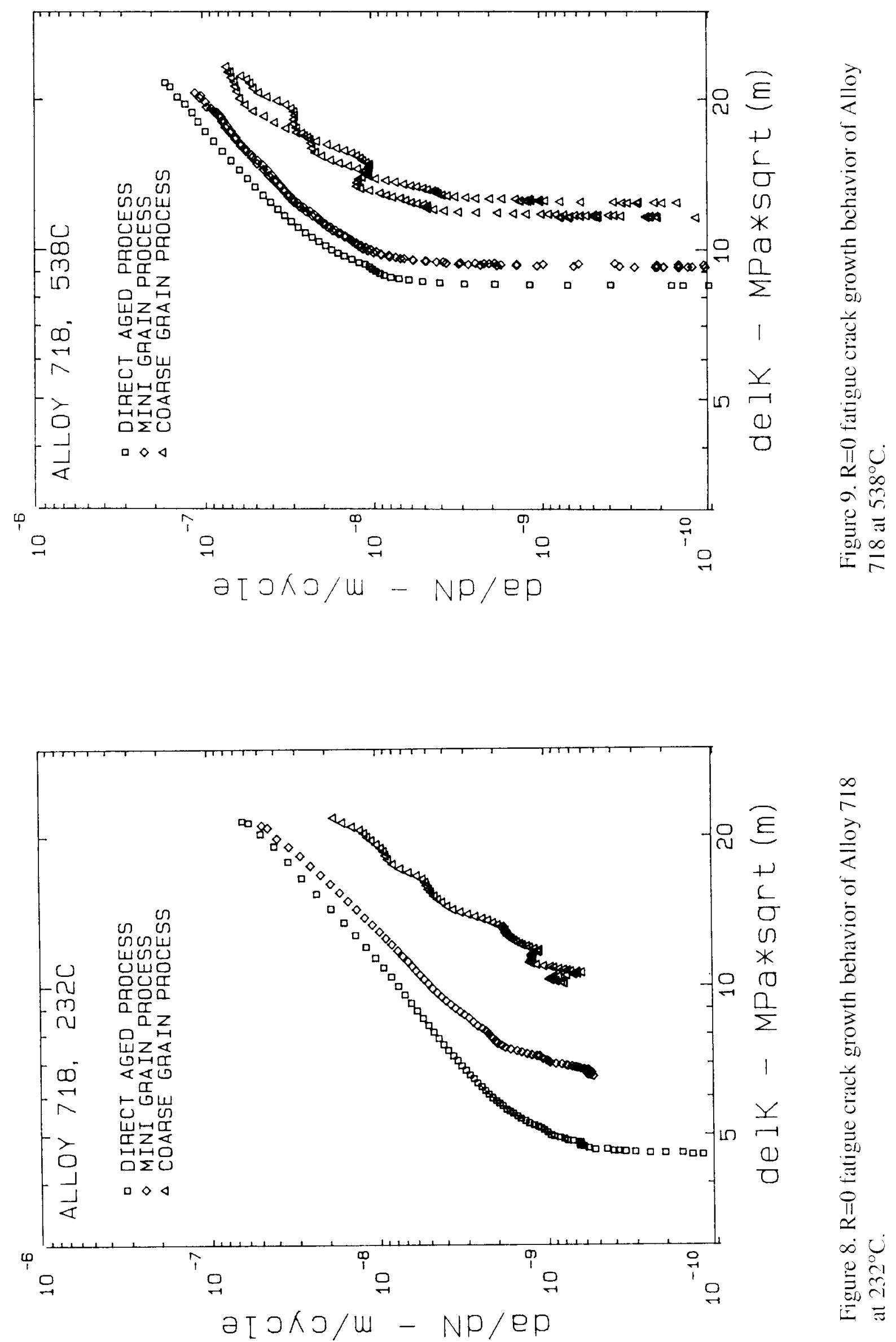
obstacles is greater. In a review paper on the effect of microstructure on fatigue crack growth behavior, this mechanism was cited as one of the micromechanisms identified with lower fatigue crack growth rates in structural alloys.[12]

With respect to the fatigue crack growth threshold, the coarse grain version of Alloy 718 exhibits the greatest increase in threshold over fine grain Alloy 718 at low temperatures; the effect diminishes with increasing temperature.

Potential contribution of crack closure

As mentioned previously, two K-decreasing segments were performed on several specimens to obtain two threshold values from a single specimen. In Figure 10 , duplicate K-decreasing segments are plotted for a mini-grain specimen tested at $538^{\circ} \mathrm{C}$. Excellent agreement is obtained in both Region I and Region II crack growth rates. A threshold value of $9.2 \mathrm{MPa}$.m was obtained for both $\mathrm{K}$-sheds. The same approach was used for a coarse grain specimen that was also tested at $538^{\circ} \mathrm{C}$. The data for the coarse grain specimen are plotted in Figure 11; again, cxcellent agreement is obtained in both Region I and Region II crack growth rates. Threshold values of 11.5 and $12.4 \mathrm{MPa}$ m were obtained for the two K-sheds (less than 10 percent difference). These results suggest that crack closure is not contributing to the observed differences in behavior between fine grain and coarse grain material. Krueger and co-workers reported that crack closure could not account for the difference between fine grain and coarse grain Alloy 718 behavior at $400^{\circ} \mathrm{C}$ [9] and at $427^{\circ} \mathrm{C}$. [11] In the study of Alloy 718 at $427^{\circ} \mathrm{C}$, the grain size effect was nearly identical for both $\mathrm{R}=0.05$ and $\mathrm{R}=0.75$ threshold testing. In addition, there was no correlation between fracture surface roughness and the measured thresholds.

The results in this investigation contrast with those reported by James [13] on Alloy 718. He did not obtain repeatable threshold values at $427^{\circ} \mathrm{C}$ when performing multiple crack arrest experiments on large specimens. However, use of the button head single edge notch (SENBH) specimen in this investigation permitted crack arrest to be obtained at small crack lengths. Typically, crack arrest occurred at a crack length of less than $2 \mathrm{~mm}$ for the first shed, and at a crack length of less than $4.5 \mathrm{~mm}$ for the second shed. Using fatigue crack growth threshold data obtained from single edge notch specimens, VanStone and Krueger [9] predicted the "critical" surface flaw size required for crack growth to occur in a round bar geometry in a companion series of LCF tests. Following testing, the fatigue origin sites were found to occur at surface carbonitrides. The "critical" surface flaw size from the fracture mechanics prediction was $1.5 \mathrm{E}$ $04 \mathrm{~mm}^{2}$, within the range of carbonitride sizes that were measured $\left(1.3 \mathrm{E}-04\right.$ to $\left.4 \mathrm{E}-04 \mathrm{~mm}^{2}\right)$. These observations suggest that the threshold values obtained from single edge notch specimens are an accurate value of the Alloy 718 threshold.

\section{Summary}

A "crossover" in fatigue crack growth rates was observed for the coarse grain and the two fine grain versions of Alloy 718 , where the value of $\Delta \mathrm{K}$ threshold at $\mathrm{R}=0$ increases with increasing icmperature. This temperature effect was greater for the two fine grain processes. The fatigue crack growth threshold of coarse grain Alloy 718 (ASTM GS 3) was greater than for two process versions of fine grain Alloy 718 (finer than ASTM GS 10) at temperatures from $24^{\circ} \mathrm{C}$ to $538^{\circ} \mathrm{C}$. The difference in the value of the fatigue crack growth threshold between fine grain and coarse grain material decreased with increasing temperature. Using the single edge notch specimen geometry, the threshold value was shown to be repeatable in both the coarse grain and mini grain processes at $538^{\circ} \mathrm{C}$. 

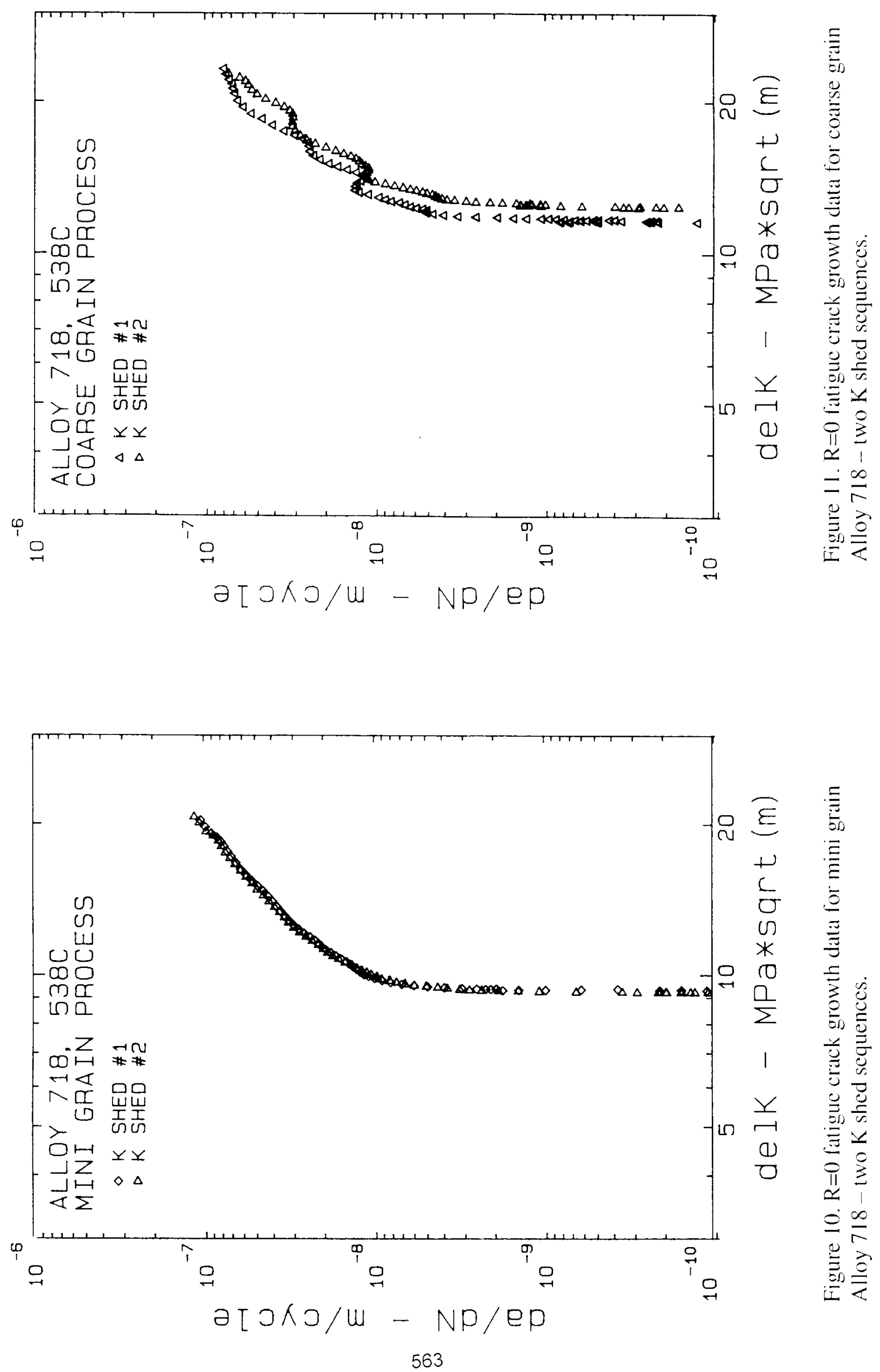


\section{References}

1. "Thermomechanical Processing of Inconel 718 and its Effect on Properties", Advanced High-Temperature Alloys: Processing and Properties, eds. S.M. Allen, R.M. Pelloux, and R. Widmer (American Society for Metals, 1986), 125-137.

2. A.W. Dix. J.M. Hyzak, and R.P. Singh, "Application of Ultra Fine Grain Alloy 718 Forging Billet", Superalloys 1992, eds. S.D. Antolovich, et al, (TMS, 1992), 23-32.

3. R.P. Gangloff, "Electrical Potential Monitoring of Crack Formation and Subcritical Growth from Small Defects", Fatigue of Engineering Materials and Structures, 4 (1981), 15-33.

4. J.R. Wilcox and M.F. Henry, unpublished research, GE Corporate Research and Development, Schenectady, New York.

5. H.H. Johnson, "Calibrating the Electrical Potential Method for Studying Slow Crack Growth", Materials Research and Standards, 5 (1965), 442-445.

6. D.O. Harris, Journal of Basic Engineering, 39, 1967, p.49.

7. M.S. Gilbert and S.N. Malik, unpublished research, GE Aircraft Engines, Cincinnati, Ohio.

8. M.F. Henry, unpublished research, GE Corporate Research and Development, Schenectady, New York.

9. R.H. VanStone and D.D. Krueger, "Investigation of Direct Aged Inconel 718 Fatigue Behavior" (Final Report NAVAIR Contract N00019-82-C-0373, Department of the Navy, Naval Air Systems Command, December 1984).

10. R.H. VanStone, O.C. Gooden, and D.D. Krueger, "Advanced Cumulative Damage Modeling" (Final Report AFWAL-TR-88-4146, Air Force Wright Aeronautical Laboratories, Scptember 1988).

11. D.D. Krueger, S.D. Antolovich, and R.H. VanStone, "Effects of Grain Size and Precipitate Size on the Fatigue Crack Growth Behavior of Alloy 718 at $427^{\circ} \mathrm{C}$," Met Trans A, August 1987, 1431-1449.

12. G.T. Gray III, A.W. Thompson, and J.C. Williams, "The Effect of Microstructure on Fatigue Crack Path and Crack Propagation Rate", Fatigue Crack Growth Threshold Concepts, eds. D.L. Davidson and S. Suresh (The Metallurgical Society of AIME, 1984), $131-143$.

13. L.A. James, "Fatigue Crack Propagation in Alloy 718: A Review", Superalloy 718 Metallurgy and Applications, ed. E.A. Loria, (The Minerals, Metals, \& Materials Society, 1989), 499-515. 